\title{
Aprender fabricando juguetes. Recorrido hacia una experiencia de educar para la paz fuera de la escuela en Argentina. ${ }^{1}$
}

\section{(Learning through toy-making: an extra-curricular educational peace education experience Argentina)}

\author{
Ana DIAMANT \\ Universidad de Buenos Aires - Facultad de Psicología \\ Sociedad Argentina de Historia de la Educación
}

\begin{abstract}
RESUMEN: La tradición pacifista del movimiento judeo progresista internacional consolidado en París en 1937 y particularmente del argentino, desde 1941, es una marca fundacional que persiste. La alternancia entre democracias y dictaduras no fueron obstáculo para que aún con restricciones, las actividades recreativas destinadas a niñas, niños y adolescentes tuvieran siempre un componente solidario e internacionalista, reconociendo el potencial aporte social de la infancia y un modo particular de entender las relaciones entre personas y con la realidad. En 1975, mientras la democracia del segundo peronismo era atacada por fuerzas paramilitares, se expandía el Plan Cóndor. Chile y Uruguay, muy cercanos territorialmente, vivían en dictadura. La proximidad geográfica y las diferencias de los tiempos de los golpes de estado hicieron que Argentina se convirtiera en refugio de exiliados y en espacio de generación de acciones solidarias y de resistencia. En ese contexto se reunieron por dos días, niños y niñas de entre 10 y 12 años para fabricar juguetes que fueron enviados a pares con sus madres presas 0 clandestinas. También se produjeron murales y esculturas tematizadas, al tiempo que se ensayaban modos de autogestión democrática de convivencia, como una particular forma de intervenir y analizar los hechos que los rodeaban.
\end{abstract}

PALABRAS CLAVE: Infancia; Pacifismo; Internacionalismo; Solidaridad; Producción.

ABSTRACT: The pacifist tradition of international progressive Judaism, which took form in Paris in 1937 and in Argentina from 1941 onwards, remains one of the movement's most

\footnotetext{
${ }^{1}$ A partir de las ponencias tituladas Una experiencia de solidaridad e internacionalismo fuera de la escuela. La propuesta de fabricar juguetes desde una institución judeo progresista argentina para niños uruguayos y chilenos (1974-1975), presentada en el XX Coloquio de Historia de la Educación "Identidades, internacionalismo, pacifismo y educación", Monforte de Lemos, Comunidad Autónoma de Galicia, julio 2019, y Una noble y gran generación, de pie hacia la realidad. Los años ' 60 y la formación de niños y adolescentes en instituciones judeo progresistas del Río de la Plata, presentada en el XXXIII ISCHE, "Estado, educación y sociedad, nuevas perspectivas sobre un viejo debate", San Luis Potosí, México, julio 2011.
} 
characteristic features. Through the succession of regimes in Argentina's recent history, the progressive Jewish institutions in the country continued to conduct their recreational activities for children and young people in the same spirit of solidarity and internationalism as always, based on their understanding of the social importance of childhood and of our relationships with other people and with the world around us. In 1975, the second Peronist regime was ousted from government by a paramilitary coup and Operation Condor was expanded. Nearby Chile and Uruguay were being ruled by dictatorship. Their geographical proximity and the time lag between coups in the different countries made Argentina a temporary refuge for exiles and a space for actions of resistance and solidarity. It was in this climate that boys and girls aged between 10 and 12 met for two days to make toys for children whose mothers were in prison or in hiding. They also created themed murals and sculptures, and workshopped democratic self-management ideas and techniques for a peaceful society as a way of reflecting on and participating in the events taking place around them.

KEYWORDS: childhood; pacifism; internationalism; solidarity; production.

\section{Itinerarios que conducen a la actividad}

El entendimiento del porqué de una experiencia -encuadrada en un proyecto sobre pacifismo e internacionalismo- realizada por niños, a mediados de los años 70 en Argentina, fabricando juguetes para pares chilenos y uruguayos con sus madres presas 0 clandestinas, obliga a recorrer por lo menos cinco itinerarios: el institucional, el geográfico, el temporal, el ideológico y el metodológico.

Cada uno de ellos, aportará perspectivas diferentes y complementarias para abordar un evento pedagógico ciertamente original y complejo del que prácticamente no han quedado registros materiales -algunos documentos y muy pocas fotos- pero sí registros en memorias de los participantes. De allí la importancia de lo testimonial en la reconstrucción y reposición de aquella actividad.

Así, la mirada desde lo institucional, sitúa a la experiencia en correspondencia con otras, del mismo arco político e ideológico.

El aporte de lo geográfico es una propuesta de viaje, da cuenta del recorrido de una inmigración y de sus inmigrantes y de sus anfitriones, que se enriquece con el discurso de lo temporal, sobre todo por las marcas de las guerras, de las tensiones entre cultura originaria y cultura de acogida y también por las alternancias entre dictaduras y democracias.

Lo ideológico actúa como una puesta simultánea de foco y de límites, marca lo central e irrenunciable, hace puente entre los marcos referenciales y los actos concretos.

Finalmente, lo metodológico transforma postulados en actividad, hace síntesis y semantiza cada acto, cada texto y sobre todo cada recuerdo.

La confluencia de itinerarios, se contextualiza en un movimiento judeo progresista convencido del mensaje a transmitir, de solidaridad, internacionalismo, pacifismo, en la Argentina de la democracia, pero, también de la Triple A (Alianza Argentina Anticomunista) 
en operación, en el continente latinoamericano avasallado por dictaduras, se consolidó, en el marco de un proyecto pedagógico en tierra fértil para planificar y llevar adelante acciones concretas, seguramente sin poder anticipar situaciones de riesgo que en poco tiempo tomaron cuerpo, a partir del golpe de estado de 1976.

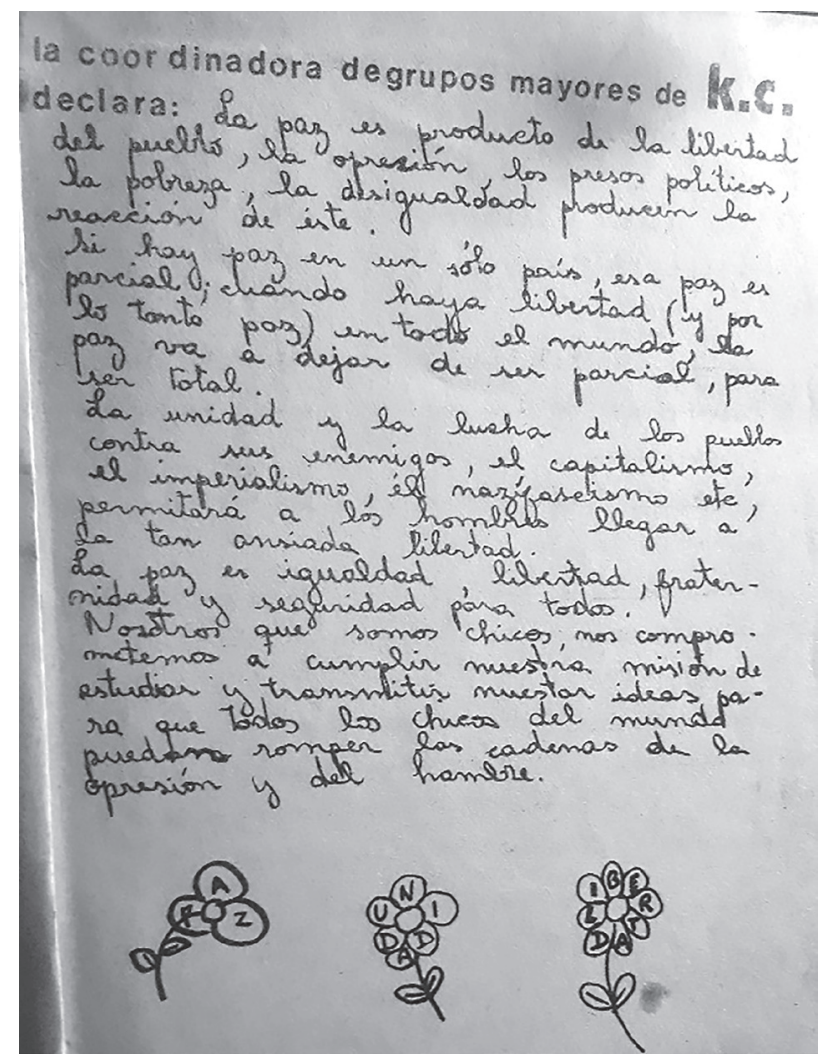

llustración 1. Convocatoria a acto por la paz. Elaboración colectiva de los representantes de los grupos de las instituciones participantes. Boletín. Mímeo, 1974, pág. 3.

\section{El primer itinerario es institucional}

La acción denominada Kinderclubeada 2 por la Paz se realiza en el marco de un conjunto de instituciones agrupadas en el ICUF -Idisher Cultur Farband / Federación de Entidades Culturales- con existencia en Argentina desde 1941 y mundial desde 1937.

\footnotetext{
${ }^{2}$ Actividad que reunió a las niñas y niños que participaban de actividades extraescolares en los kinderclub clubes infantiles- de las instituciones federadas en el ICUF.
} 
Desde las primeras décadas del siglo XX, se fundan organizaciones urbanas ${ }^{3}$ judeo progresistas en el Río de la Plata, con el propósito de agrupar, dar contención, apoyo, educación y difusión cultural a inmigrantes judíos procedentes especialmente de Europa Central.

Los sectores laboriosos, populares, crearon instituciones culturales y sociales con una concepción militante [...] que a más de su propia labor de difusión cultural y esclarecimiento, recreativa y asistencial, fueron y son fuente de experiencias donde las masas aprenden a actuar, dejando de ser meros receptores de los acontecimientos político-sociales que les atañen, para pasar a ser factores que influyen sobre los acontecimientos, que los dirigen y condicionan. ${ }^{4}$

Se conformaron así escuelas idiomáticas, clubes infantiles y juveniles, colonias de vacaciones y campamentos que convocaron a niños nacidos en estas tierras junto a inmigrantes e hijos de inmigrantes, refugiados y exiliados por motivos económicos y políticos, por persecución antisemita o por su militancia anarquista o en los partidos comunistas y socialistas europeos, además de propuestas culturales para adultos.

En todos los casos las actividades tensaban la relación entre la preservación de la cultura de origen y la integración con la cultura receptiva, con una clara postura política de sumarse a las luchas populares, entre lo nacional e internacional que permitiera tanto participar de la vida cotidiana en la nueva tierra como mantener las raíces que se portaban desde sus lugares y experiencias de procedencia. $^{5}$

La concurrencia a la escolaridad pública, obligatoria y universal, nunca estuvo en cuestión para este movimiento, por el contrario, su defensa fue una de las banderas irrenunciables $^{6}$, con el fundamento, además, de mantener a las niñas y niños en relación con un contexto más abarcativo que el comunitario, a la que se sumaban los espacios educativos propios, con enfoques político laico, cultural idishista ${ }^{7}$ y pedagógico hibridado entre lo moderno y escolanovista y lo exitoso de las experiencias pedagógicas del campo socialista. ${ }^{8}$

\footnotetext{
${ }^{3} \mathrm{~A}$ diferencia de otras, antecesoras, radicadas en el medio rural, que adoptaron la forma de colonias agrícolas ${ }^{4}$ AAVV, Tesis de la Conferencia Sudamericana del ICUF (Montevideo: Edición de la Federación de Entidades Culturales Judías, 1967), 6.

5 "Las colectividades judías [progresistas] en nuestros países han arraigado profundamente -aun cuando en distintos grados- en la vida nacional de los respectivos pueblos a los cuales nos integramos. Las propias causas que motivaron la emigración masiva desde los países de origen (miseria, discriminación económica y social, persecuciones) y la característica social de la inmensa mayoría de esa masa inmigrante -obreros, artesanos, campesinos- condujeron por un lado a buscar una consolidación económica y un clima político propicio, que ofrecieron garantías de estabilidad y tranquilidad; por el otro lado ya al propio tiempo condujeron a los sectores avanzados de esa masa laboriosa a organizar su vida cultural, societaria y aún económica bajo el signo del progreso y a contribuir por su intermedio y/o en forma individual, a las luchas democráticas de los pueblos con quienes convivimos". Ibidem, 4.

${ }^{6}$ Nerina Visacovsky, Argentinos, judíos y camaradas tras la utopía socialista (Buenos Aires: Biblos, 2015), 130.

${ }^{7}$ Cultura judía de la diáspora en lengua idish.

${ }^{8}$ Ver referencias a experiencias exitosas de educación no formal en el campo socialista que han impactado en las propuestas pedagógicas de la instituciones icufistas en:

Ana Diamant, "Génesis y continuidad de un proyecto de educación no formal en el tiempo libre. Testimonios de 60 años de la colonia Zumerland en Argentina", Anuario de Historia de la Educación, 12 (2012): 209-336.

Ariel Tokman, "De Gorki a Zumerland y de la U.R.S.S. a Mercedes: Diálogos históricos entre pedagogías disonantes", Anuario de Historia de la Educación, 19 (1) (2018): 66-85.
} 
Con el paso del tiempo, los cambios generacionales, la consolidación económica que se operó a partir del crecimiento de muchas familias en el comercio y la industria, las ofertas educativas que mantuvieron su centralidad ideológica, fueron adoptando otras formas en función de nuevas demandas.

El aprendizaje del idish ${ }^{9}$ dejó de ser un objetivo, en la medida en que la lengua perdió primacía en la intimidad de los grupos y familias. La aparición de las escuelas estatales de jornada completa también fue un factor de debilitamiento para las escuelas idiomáticas, considerando además que este sector de la colectividad se opuso a la creación de escuelas comunitarias integrales, justamente por su apoyo incondicional a la escuela estatal.

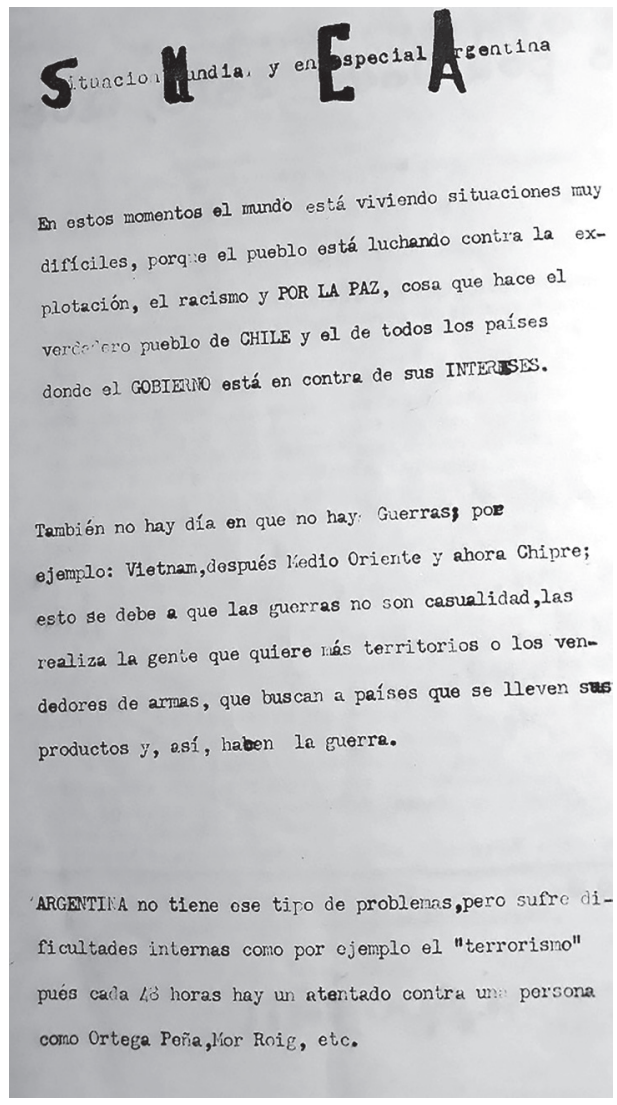

llustración 2. Nota de escritura colectiva. Alumnos de la Escuela Idiomática I. L. Peretz de Villa Lynch. Provincia de Buenos Aires. Boletín Columnas Juveniles. El diario de los chicos que lo leen hasta los grandes. Mímeo (ca. 1970), pág. 9.

\footnotetext{
${ }^{9}$ Lengua hablada por los judíos de la Europa Central que se dispersa por el mundo con sucesivas migraciones y exilios.
} 
La misión ideológico pedagógica la asumen entonces los clubes infantiles (kinder clubs) y juveniles, las colonias de vacaciones y los campamentos guiados por la idea de formar niños y adolescentes -adultos en perspectiva-comprometidos con la realidad que los rodeaba y sensibles a las transformaciones sociales. ${ }^{10}$

En estas actividades, como antes en las escolares, el sostén teórico que las fundamentaba incluía desde Wallon y Vigotsky hasta Makarenko y Korchak, desde Decroly y Montessori hasta Paulo Freire, Tzalel Blitz y Berta Braslavsky, a las que se fueron sumando, a partir de los años 60, los aportes de la sociología cultural francesa, la psicología social, el psicoanálisis y la pedagogía crítica.

\begin{abstract}
La solidaridad era algo que trabajábamos desde los chicos de 4 años en las actividades [...] hasta los más grandes de los grupos adolescentes; desde una ronda de intercambio a cómo se armaban pequeños grupos para desarrollar cosas. Y el internacionalismo también era un tema que estaba presente. Primero fue con Uruguay y Chile que tuvieron las dictaduras antes que nosotros [...] y era una fuerte militancia vinculada con este tema de la solidaridad. Había un lema que teníamos: 'Hermano chileno no bajes la bandera que aquí estamos dispuestos a cruzar la cordillera' y en ese momento había una movilización importante desde los grupos y desde quienes teníamos esta labor pedagógica porque, en realidad, siempre era tomado el tema de enseñar en nuestras instituciones como una actividad de militancia. ${ }^{11}$
\end{abstract}

Es en el contexto de esta proyección institucional que se desarrolla la actividad en solidaridad con los pueblos que luchan por la paz en la Latinoamérica atravesada por los golpes de estado y el avance de los operativos paramilitares en 1975.

\title{
El segundo itinerario es geográfico
}

El proceso migratorio judío de personas, pero también de instituciones hacia el Río de la Plata, que se inicia en la Europa Central, se concentra en una oleada entre guerras (ca. 1930), se va diluyendo después de la segunda guerra mundial y reaparece con características diferentes en los exilios de los años 70 en América Latina.

El ICUF se funda en París, en 1937, en el marco del Primer Congreso Mundial de la Cultura Judía. Para entonces, ya residían fuera del continente europeo migrantes judíos europeos, perseguidos en sus lugares de origen por cuestiones religiosas, ideológicas, económicas, agrupados en instituciones comunitarias que respondían a corrientes de pensamiento distanciadas de lo religioso, comprometidas ideológicamente con las izquierdas, con propósitos benéficos y con vinculaciones con organizaciones del movimiento obrero nacional. $^{12}$

Ya en Polonia no podíamos estar, nos seguían los pasos, siempre pensando que mañana nos pueden venir a buscar, así pasaba también con nuestros amigos [...] Llegamos a Brasil cuando fue la revolución de Prestes. Nos ubicamos en San Pablo. En ese tiempo falleció mi tía y después de la revolución se cortó toda posibilidad de trabajo en fazenda. Me ofrecieron trabajar en la comunidad, en la Casa del

\footnotetext{
${ }^{10}$ Zumerland Colonia de Vacaciones. Buenos Aires: Ediciones Colonia, ca. 1962-65, pág. 36.

${ }^{11}$ Guillermo Golzman, docente participante de la kinderclubeada 1975. Testimonio oral. (Buenos Aires: 2012).

${ }^{12}$ Carolina Kaufmann et.al., Shules y ateneos. Huellas de la educación no formal judeorosarina. (Rosario:

Editorial Laborde, 2008), 59.
} 
Pueblo o en Hebraica como maestra y además daba conferencias. Hay casualidades en la vida que uno nunca piensa que pueden pasar... Leyendo el diario -ilo que es leer el diario todos los días!- salió la noticia que estaba de visita en San Pablo el director de la J.C.A. (Jewish Colonization Asociation) que tenía colonias en Brasil y también en la Argentina. Se presentó mi esposo en su hotel sin entrevista previa fijada y como sabía hablar en francés, le contó que buscaba ubicarse, que buscaba trabajo. iA los seis días recibió un pasaje para viajar a la Argentina. ${ }^{13}$

Muchos de los participantes de esas organizaciones, estuvieron involucrados en la creación de sindicatos, inexistentes hasta entonces, especialmente madereros y textiles, en función de sus ocupaciones previas ${ }^{14}$-con la particularidad de que tanto en Argentina como en Uruguay, en algunos casos, sus actas fundacionales están escritas en idish y que los periódicos que publicaban contaban con secciones escritas en esa lengua. ${ }^{15}$

Los integrantes de esos agrupamientos tuvieron participaciones destacadas en las luchas reivindicativas por la mejora de las condiciones laborales, en la creación de partidos políticos comunistas y socialistas ${ }^{16}$ y en causas más allá de los nuevos límites territoriales, entre ellas las Brigadas Internacionales Judías ${ }^{17}$ combatiendo en defensa de la República Española $^{18}$, la militancia en el Socorro Rojo Internacional ${ }^{19}$ en apoyo a las acciones del ejército soviético y en Acción Antinazi. ${ }^{20}$

Como antecedente al evento fundacional del ICUF, es necesario destacar que dos años antes, también en París, en búsqueda de alianzas antifascistas y antibélicas, había tenido lugar el Congreso Internacional de Escritores en Defensa de la Cultura, convocado por figuras como Romain Rolland, Henry Barbuse, Bernard Shaw y Máximo Gorky y que ambos sesionaron en la Maison de la Mutualité. ${ }^{21}$

El Manifiesto fundacional del Primer Congreso Mundial de la Cultura Judía retoma contenidos de su antecesor -el de la cultura mundial- y los focaliza de acuerdo a sus intereses, reuniendo a delegaciones de 23 países, destacando que:

el momento presente es profundamente trágico en la vida del pueblo judío. Las oscuras fuerzas de la reacción y el fascismo, en su cruzada contra todas las fuerzas vivas progresistas del mundo contemporáneo, hicieron del pueblo judío el blanco de sus particulares ataques. La existencia misma del pueblo judío está amenazada en una serie de países del mundo. ${ }^{22}$

\footnotetext{
${ }^{13}$ Leike Kogan, testimonio oral, "Una conversación con Dora Korman", en Ana Diamant y J. Feld, Zumerland Colonia, Proyecto, memorias (Buenos Aires: Ediciones CER, 2000), 77.

${ }^{14}$ Daniel Kersfeld, Rusos y rojos. Judíos en los tiempos de la Comintern (Buenos Aires: Capital Intelectual, 2012), 98.

${ }^{15}$ Pinie Katz, Páginas selectas (Buenos Aires: Editorial ICUF, 1980), 98.

${ }^{16}$ Hernán Camarero, Tiempos rojos (Buenos Aires: Sudamericana, 2017), 120 y 188.

${ }^{17}$ La Brigada Botwin que participó en la Guera Civil Española estaba integrada por combatientes judíos. Su nombre recuerda a un judío polaco, Naftali Botwin, asesinado por la policía polaca en 1925.

${ }^{18}$ Dina Lida Kinoshita, "O ICUF como uma rede de intetectuais", Revista Universum, 15 (2000), 380.

${ }^{19}$ Servicio Social para la atención de prisioneros comunistas, creado por la Internacional Comunista en 1922.

${ }^{20}$ Movimiento de ayuda a los ejércitos aliados en la lucha contra el nazismo.

${ }^{21}$ Situada en el Barrio Latino, sede, en esa época y hasta muchos años posteriores de gran parte de los eventos convocados por la izquierda francesa moderna.

${ }_{22}$ Manifiesto, Primer Congreso Mundial de la Cultura Judía, 1937 (Buenos Aires, Mimeo, 1967), en La Educación en las Entidades del ICUF. Pasado, presente y futuro (Buenos Aires, 2011), 7.
} 
La Argentina y el Uruguay estuvieron representados por Pinie Katz ${ }^{23}$, militante intelectual que presidió el ICUF nacional cuando se crea en 1941, quien logró llegar a París por el trabajo que realizó el "Comité Organizador Argentino Pro Envío de un Delegado al Congreso de la Cultura" que recaudó los fondos necesarios. ${ }^{24}$

Los principios fundacionales de "defensa, difusión y desarrollo de la cultura judía sobre una plataforma de lucha contra el fascismo y la guerra, contra el oscurantismo, por el laicismo y el humanismo, por un nuevo mundo liberado con un orden de justicia social"25 se mantienen con el paso del tiempo, mientras se aggiornan de acuerdo a contextos epocales.

En los años 70, los propósitos de generar redes de solidaridad y sociabilidad se manifiestan -no sin tensiones con la "calle judía"- en el impulso a actividades en las causas sociales de la "calle nacional" y en generar estructuras socio-educativas que garanticen la conformación identitaria de las nuevas generaciones, ahora ya nativas y en muchos casos hijos de nativos.

\begin{abstract}
Nos llamamos judíos argentinos a plena conciencia, con entera fe y convicción total de lo que somos y con nuestro más fervoroso deseo de serlo. Nosotros, quiero decir los judíos que aquí han nacido y los inmigrantes que nos radicamos y ligamos al país nuestro destino y nuestro porvenir y que amamos al país como se ama lo que uno ha creado o ayuda a perfeccionar, como se ama el hogar levantado con las propias manos. ${ }^{26}$
\end{abstract}

Se presenta sí una nueva geografía, ahora en tierra de acogida, que actualiza los debates entre quienes eligen incorporarse a las organizaciones y las luchas generales de los pueblos a los que llegan, con lenguas y hábitos diferentes a los portados, y quienes eligen reproducir y sostener los modos de organización comunitarias que atiendan necesidades estructurantes de identidad y garanticen la transmisión de ideologías y valores, ya no de lengua idish.

La acción solidaria de niñas, niños y docentes de las instituciones judeo progresistas de fabricar juguetes y enviarlos a otras y otros desconocidos, pero padeciendo la injusticia frente a la que los postulados fundacionales se expresaban sin ambigüedades, se enmarca en este proyecto.

\title{
El tercer itinerario es temporal
}

Recupera los dos anteriores y discurre en contextos y espacios de persecución -no sólo antisemita- entre el impacto que dejó la denominada Gran Guerra, la amenaza de un nuevo conflicto bélico, la llegada a nuevas tierras y el devenir de la política de la región.

\footnotetext{
${ }^{23}$ Pinie Katz (1881, Groseles, cerca de Odesa - 1959, Buenos Aires). Fundador del Diario Di Prese (en idish). 1929: viaja a la URSS. 1937: viaja a París al congreso fundacional del ICUF. 1941: participa de la fundación del ICUF en Argentina y lo preside. 1952: Viaja a Viena al Congreso de la Paz.

${ }^{24}$ Libro de Actas. Comité Provisorio para una Federación de la Cultura Judía en Argentina (1937-1940) Traducción Isaac Rapaport. (Buenos Aires: Ediciones CeDoB Pinie Katz, 2019), 15.

${ }^{25}$ AAVV, "EI ICUF. Pujante movimiento judeo progresista", en X Congreso (Buenos Aires: Edición de la Federación de Entidades Culturales Judías de la Argentina, 1972), 42.

${ }^{26}$ Katz, Páginas selectas, 10.
} 
Entre tanto, cada tiempo reclama diferentes estructuras y acciones, en la medida en que se agranda la distancia entre el shtet ${ }^{27}$ de procedencia y la vida urbana rioplatense. $\mathrm{Ni}$ las necesidades ni las acciones son las mismas cuando se vive y se piensa en territorios hostiles a los judíos que los responsabilizaban de los problemas socio-económicos y étnicos que se suceden al tiempo que crece la población de obreros fabriles -y también la desocupación- y las luchas obreras y anticapitalistas ${ }^{28} 0$ cuando se trata, desde la condición de extranjero, de asumir otra cultura, atravesar otras experiencias, además de haber atravesado el Océano Atlántico.

La renovación teórica y metodológica de las propuestas recreativas fue un estímulo ante la declinación de la escolaridad comunitaria. Se produce en un tiempo de recambio generacional y de incorporación de profesionales formados en la Argentina a los equipos pedagógicos, reemplazando en parte al activo voluntario o a los preparados en Europa, que se asumen, desde otras perspectivas, como garantes de la continuidad en la transmisión de los contenidos judíos y progresistas.

El desafío de formar nuevos cuadros docentes y militantes intenta salvar la discusión y por ende la continuidad de los jóvenes entre la asimilación -activar dejando de lado lo judío y enraizarse en lo nacional- o la integración -tomar lo judío e incorporarlo a lo nacional. ${ }^{29}$

Esto implicó procesos de revisión del lugar y del contenido de la herencia cultural y un nuevo concepto para la identidad judía, progresista, nacional e internacional, de cara a las nuevas realidades sociales, políticas y económicas en Argentina y en el mundo, a otras prácticas militantes, intelectuales y culturales, de la mano del afianzamiento del campo socialista de los años 50 y del impacto de la revolución cubana en los 60 . También de las alternancias entre democracias y dictaduras de los $70 .{ }^{30}$

Ningún movimiento ni organización judía democrática, sea social o cultural puede desentenderse de la realidad política que vive el país. Es decir, debe tomar posiciones de lucha contra la reacción y participar con todos los medios en el afianzamiento de las fuerzas democráticas.

En este tiempo, las producciones sobre el impacto del capitalismo y del consumismo ponen al tiempo libre en el lugar de un tiempo problemático y reconocen la necesidad de proteger los espacios de ocio -por oposición a negocio ${ }^{31}$ - creativo, promover las tareas de responsabilidad social tanto dentro como fuera de las estructuras comunitarias.

Estos debates -y también las experiencias que se generaron a partir de ellos- no son patrimonio del movimiento icufista. Por el contrario se retroalimentan con otros promovidos por instituciones universitarias, sindicatos, comunidades eclesiásticas, activistas

\footnotetext{
${ }^{27}$ Shtetl, en idish, pequeño poblado urbano. Expresión utilizada con cierta melancolía por los inmigrantes judíos de la Europa Central en referencia a su lugar de origen.

${ }^{28}$ Dina Lida Kinoshita, "O ICUF como uma rede de intetectuais", Revista Universum, 15 (2000): 377.

29 "A la Icufiada, Salud!", Revista Tiempo, 59 (1973): 11.

30 "Pasar a la ofensiva", Revista Tiempo, 48 (1972): 20.

${ }^{31}$ Joffre Dumazedier (Francia, 1915-2002). Sociólogo del ocio y de la cultura. Autor de Hacia una cultura del ocio (1962) y La Revolución cultural del tiempo libre (1990).
} 
voluntarios en villas miseria y barrios marginales, instando en todos los casos a hacer lecturas críticas de la realidad ${ }^{32}$, a prácticas solidarias, a confiar en las virtudes de la educación y del conocimiento, a defender las experiencias democráticas, a contrarrestar situaciones de desigualdad e inequidad al amparo de relaciones de poder autoritarias. Era necesario contar con niños, adolescentes y jóvenes que fueran, además de sensibles a las dramáticas sociales, creadores de respuestas consistentes con las demandas comunitarias y populares. ${ }^{33}$

En los 60 y 70, con el avance de la represión antidemocrática en la región, las acciones pedagógicas desarrolladas por estas instituciones palpitaron al ritmo de los acontecimientos políticos del país y de Latinoamérica, mientras se consolidaban alternativas gubernamentales de nuevos rumbos, que resultaron luego avasalladas por la violencia estatal y la coordinación represiva y que hicieron lugar al avance del Plan Cóndor. ${ }^{34}$

En ese tiempo conviven primero la Argentina con un breve período democrático conocido como la "primavera" de Cámpora (1973), debilitado por los gobiernos de Perón y de su esposa Isabel (1973-1976), Chile con el gobierno de Allende (1970-1973) y Uruguay con el fin de su democracia (1973).

Las diferencias de los tiempos en que se dieron los golpes de estado ${ }^{35}$ en Chile y Uruguay, favorecieron que Argentina se convirtiera en refugio para los perseguidos de la región y a la vez espacio de organización de resistencia y acciones solidarias, al menos hasta su ruptura institucional (1976) y a partir de entonces se transformó en una trampa por demás riesgosa para las personas y las instituciones ${ }^{36}$, con un saldo de 30.000 desparecidos y números muy altos de exiliados e insiliados, con instituciones clausuradas 0 funcionando en la semiclandestinidad.

Un aprendizaje que tiene que ver con el ida y vuelta, que hoy estamos aquí, mañana estamos para allá, lo cual ocurrió efectivamente. Porque esto de la kinderclubeada pasó en un período muy convulso de la historia argentina pero al mismo tiempo, con cierta garantía democrática que ni Chile ni Uruguay

\footnotetext{
32 "Cuando fueron a visitar la metalúrgica, camino a Luján, los maestros entretuvieron a los capataces para que los chicos pudiesen entrevistar a los obreros. ¿Cuál era la intención? Que los chicos tuvieran un verdadero contacto, porque los capataces querían hacer una visita guiada y mostrar las máquinas, y nosotros pensábamos que de las máquinas hay fotos, pero de los hombres no. Queríamos a los hombres." A. Pain, testimonio oral, noviembre 1999. En A. Diamant y J. Feld, Zumerland Colonia. Proyecto, Memorias. (Buenos Aires: Ediciones CER, 2000).

${ }^{33}$ Silvia Brusilovsky, "Recuperando una experiencia de democratización institucional y social: la extensión universitaria en la Universidad de Buenos Aires (1955 - 1966)", Revista de Investigaciones del Instituto de Ciencias de la Educación, 12 (1998): 31-41.

${ }^{34}$ El Plan Cóndor fue una operación represiva que actuó desde comienzos de los '70 -materializó persecuciones, asesinatos y desapariciones- de la que participaron los servicios de inteligencia de los países del Cono Sur: Argentina, Bolivia, Brasil, Chile, Paraguay y Uruguay en coordinación con la Agencia Central de Inteligencia (CIA) de los Estados Unidos. El principal objetivo que se planteó fue la lucha contra el comunismo y otras formas de subversión. Operó intercambiando información sobre personas y acciones entre los servicios y reforzando la actuación de las fuerzas de seguridad de los gobiernos dictatoriales.

${ }^{35}$ Dictadura en Chile 1973-1990. Dictadura en Uruguay 1973-1985. Dictadura en Argentina 1976-1983.

${ }^{36}$ Ana Diamant y Silvia Dutrenit. "La militancia clandestina uruguayo porteña: comunistas en el exilio", Revista Estudios, (2017): 52-53.
} 
tenían en ese momento, o ciertas posibilidades de comunicación o de expresión que ni Chile ni Uruguay tenían en ese momento y que Argentina no lo tuvo en muy poquito tiempo después. En el 75 todo lo que hacíamos nosotros era visto como subversivo y de hecho lo era en el término estricto de la palabra subversivo. Nosotros pretendíamos subvertir determinados conceptos de la sociedad que afortunadamente se han subvertido. ${ }^{37}$

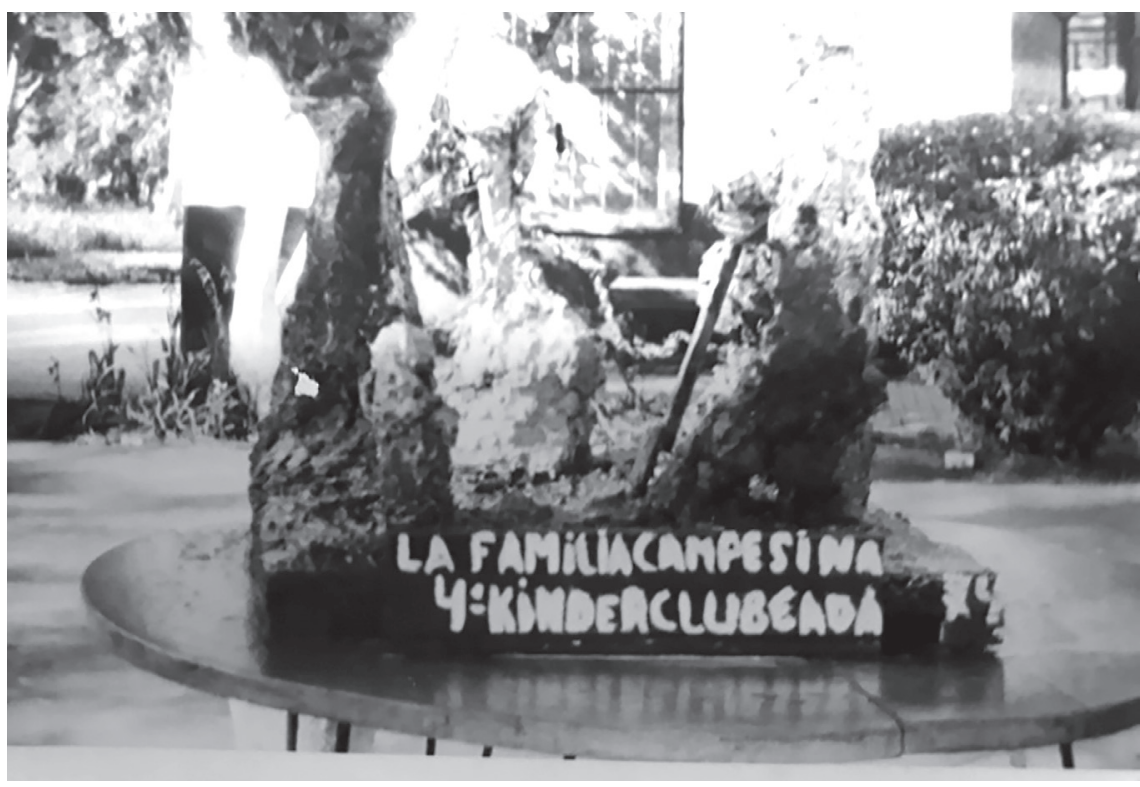

Ilustración 3. La familia campesina. Escultura en alambre y papel maché. Producción colectiva. Kinderclubiada, 1975.

En ese contexto y durante cuatro años -1972-1975- se realizaron las kinderclubeadas, al calor de una democracia que se iba perdiendo, pero única entre los países cercanos. Allí se planteó, desde una coordinación promovida por el ICUF que niñas y niños procedentes de varias instituciones ${ }^{38}$ de la Ciudad y la Provincia de Buenos Aires se agruparan, interactuaran, analizaran e intervinieran, en la medida de sus posibilidades sobre hechos sociopolíticos que los rodeaban. En una oportunidad se centró en el juego deportivo no competitivo, en otra se trabajó en torno a la producción de murales, en otra en relación con la música y las canciones y en la última, que se realizó en una convivencia de cuarenta y ocho horas en la Colonia Zumerland ${ }^{39}$, se intervinieron paredes a través de murales -que

\footnotetext{
${ }^{37}$ Pablo Schimilovich, docente participante de la kinderclubeada, 1975. Testimonio oral. Buenos Aires: 2011.

${ }^{38}$ Participaron niñas, niños, docentes y activistas del ICUF y de las instituciones Zhitlovsky, Sarmiento, Scholem y Ringelblum de la Ciudad de Buenos Aires y Mendele de San Martín, Peretz de Villa Lynch, Peretz de Lanús y Centro Cultural Israelita de Ramos Mejía de la Provincia de Buenos Aires.

${ }^{39} \mathrm{La}$ colonia Zumerland fue fundada en la ciudad de Mercedes, Provincia de Buenos Aires, hace casi setenta años, como uno de los espacios icufistas para desarrollar actividades al aire libre, en contacto con la naturaleza,
} 
aún perviven en el espacio en el que fueron creados-, se realizaron esculturas tematizadas y se fabricaron los juguetes que luego se enviaron en forma clandestina a niñas y niños que tenían a sus madres presas o compartían con ellas la condición de cautiverio: "Entre las actividades artístico-plásticas [... hicimos una grande y trabajosa escultura con cemento y alamabre, luego de hablar sobre las familias campesinas que en Chile eran perseguidas". ${ }^{40}$

\section{El cuarto itinerario es ideológico}

El eje temático que atravesó la experiencia fue la solidaridad con los pueblos que luchan por la paz, en este caso, materializado en la solidaridad con niñas y niños de Chile y Uruguay y sus familias. Un contenido no ajeno a una comunidad que décadas antes, por efectos de la guerra debió generarse y organizarse en una nueva tierra, con otra lengua, con otras habitualidades y otras institucionalidades y se debatió entre la preservación de su acervo -que incluye el idish- sus antecedentes de militancia y activismo y las reglas circunstanciales que propuso el nuevo territorio y su política.

Si quiero un ICUF que de pronto brinde a los niños esta visión de solidaridad, de construcción en una comunidad internacional de la que uno forma parte, de una visión de la paz, tengo que ir necesariamente a la sensibilización. Cuando hablo de sensibilización hablo de un proceso didáctico y metodológico que permita abrir de tal manera la razón y la emoción para que ingrese el constructo verdaderamente significativo que constituya finalmente un aprendizaje; no le veo otro camino y miro hacia atrás y digo el camino fue recorrido así. ${ }^{41}$

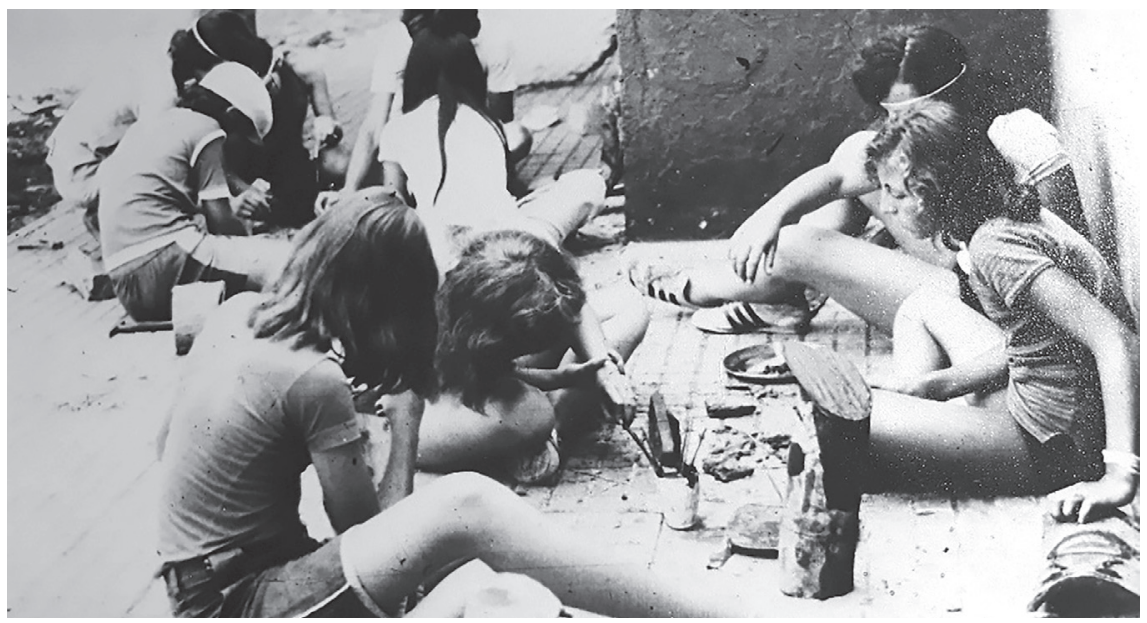

Ilustración 4. Niñas y niños en proceso de producción colectiva. Colonia Zumerland. 1975.

en convivencia de niñas y niños, alejados de sus familias durante 20 días. Aún sigue en funcionamiento.

${ }^{40}$ Silvia Poliakoff, La re-creación y re-construcción del mural de la canilla del medio. La historia contada a los grupos (Buenos Aires: Mimeo, 2010), 2.

${ }^{41}$ Inés Moreno, Directora general de la kinderclubiada 1975, Testimonio oral (Buenos Aires: 2012). 
La organización para la convivencia y la producción se estructuró en torno a la recuperación de un modo propio y ciertamente original para el medio nacional de concebir a la infancia, una particular forma de entender la vida grupal, los modos de vincularse niños, jóvenes y adultos entre sí y con la realidad, una consideración "moderna" sobre el tiempo libre y su uso y el reconocimiento de la posibilidad del aporte social del niño y del adolescente, creando un clima y una producción que aún hoy es recordada por participantes como marca en la historia personal. Alli se pusieron en acto formas de explorar el mundo y también de cambiarlo; ensayos para encontrar los límites entre lo autorizado, lo aceptado y sus correspondientes contraejemplos; criterios para establecer juicios valorativos y hacerse cargo de las consecuencias, junto al placer, la aventura y la búsqueda de modelos de identificación. ${ }^{42}$

El hombre nuevo y un mundo mejor, tanto para quienes habían vivido la experiencia de la guerra y sus marcas desde Europa, como para quienes miraban con expectativas al mundo socialista y con preocupación los avances dictatoriales en América Latina, eran objetivos en el imaginario y en las tareas la dirigencia icufista que valoraba especialmente la transmisión generacional y la formación de cuadros.

La literatura pedagógica soviética y en menor medida la cubana -aunque no sólo ellas- daban cuenta de experiencias y fundamentos que aproximarían a esa construcción. La producción de Antón Makarenko ${ }^{43}$ y sus acciones en la Colonia Gorky es recibida y reversionada como uno de los pilares de una nueva pedagogía. Destaca la importancia de la solidaridad y el compromiso sobre tareas propias, con los cercanos y también con desconocidos, la supremacía de los intereses colectivos sobre los individuales, la producción concreta y su perdurabilidad y la ocupación organizada del tiempo libre.

Para esta actividad, $4^{\text {a }}$ Kinderclubeada, en la cual todos nos hemos embarcado, ya que la realización depende de los esfuerzos de cada uno de nosotros, necesitamos, por la envergadura y la diversificación de las tareas y por las normas a las cuales nos ajustamos, un marco de referencia muy claro. Nuestra tarea es estar permanentemente con los chicos en la actividad (...) Esto porque la actividad planificada tiene como requisito la flexibilidad, es necesario estar permanentemente informados de los cambios que se realicen. En caso de duda y frente a cualquier eventualidad, remitirse a los responsables de cada área. ${ }^{44}$

Se sumarán luego, también, desde la Europa no socialista, aportes como los de la sociología cultural francesa, ${ }^{45}$ que incorpora el análisis reflexivo sobre la autogestión en relación con la convivencia y la responsabilidad personal y colectiva, junto a la libertad como oportunidad para intervenir en los espacios, promover las deliberaciones y decisiones colectivas y transformar los derechos formales en reales.

\footnotetext{
${ }^{42}$ Ana Diamant, "Génesis y continuidad de un proyecto de educación no formal en el tiempo libre. Testimonios de 60 años de la colonia Zumerland en Argentina", Anuario de Historia de la Educación, 12 (2012): 5.

${ }^{43}$ Entre sus obras se destacan: El camino de la vida (1930); Poema pedagógico (1933-1935); Banderas sobre las torres (1938).

${ }^{44}$ Instructivo elaborado por el equipo de conducción de la actividad entregado a docentes y voluntarios participantes. Incluye además horarios de actividades, normas de convivencia y de higiene personal, recursos para la conducción de los grupos y materiales disponibles para la realización de las tareas. Pág. 1.

45 Joffre Dumazedier (1915-2002). Sociólogo francés. Considerado pionero en los desarrollos sobre sociología del ocio.
} 
[...] la juventud quiere romper con las normas tradicionales de vida, y quiere también desempeñar su papel activo, allí donde se siente directamente responsable (...) Los movimientos de juventud superaron ya la etapa de la función puramente recreativa, y se constituye en una fuerza impulsora de todos los movimientos que bregan por superar las estructuras de la sociedad actual $[\ldots]^{46}$

La pedagogía de la liberación latinoamericana, sobre todo en la palabra de Paulo Frei$\mathrm{re}^{47}$, en oposición a la consideración bancaria de la educación, traerá las ideas que posicionan a los individuos como seres críticos y reflexivos de la realidad, creadores a partir de sus propios conocimientos, alejados de la reproducción sin comprensión, destacando el diálogo, las oportunidades de encuentro, la reflexión en común, la toma de conciencia de la existencia de fuerzas determinantes de la cultura que impiden la realización plena.

\begin{abstract}
Mientras te preparas para esta nueva tarea debes pensar en lo que aportarás a la creación de este ambiente educativo. Harás recuento de todo lo que sabes, de las canciones que recuerdas, de los juegos que conoces, de los trabajos que te animas a realizar, de tus experiencias de camping 0 de campamento, de los chistes o bromas que permiten alegrar el ambiente, en fin, será un remozar de todas tus posibilidades y capacidades juveniles (...) Los niños verán en ti a muchas personas a la vez (...) Verán en ti a un guía no impuesto por ninguna autoridad, sino por el peso propio del conocimiento y la experiencia. ${ }^{48}$
\end{abstract}

\title{
El quinto itinerario es metodológico
}

En un país con una larga historia de persecuciones, proscripciones a las organizaciones progresistas y a partidos políticos y con varias experiencias de golpes de estado, la cuestión de la consolidación y preservación de los archivos institucionales es un tema complejo, sobre todo al momento de intentar reponer trayectorias y experiencias.

Por otra parte, la particularidad de que muchas de sus primeras producciones fueron escritas en idish, lengua que hoy cuenta con muy pocos lectores, constituye un problema adicional.

EI ICUF y las instituciones que se federan en torno a él, no sostuvieron una política sistemática de conformación y conservación de archivos -sí de bibliotecas- y se vieron obligados a tomar decisiones, en períodos de restricción democrática, de esconderlos, distribuirlos 0 destruirlos sistemáticamente, sobre todo donde figuraban nombres propios, como una forma de cuidado para con su gente.

Al día de hoy se trabaja en la recuperación documental de la historia a partir de la sistematización de archivos personales y familiares que han permanecido resguardados

\footnotetext{
${ }^{46}$ Conclusiones. Plenario Nacional de la Juventud del ICUF (Buenos Aires, 1974), 13.

${ }^{47}$ Pedagogo brasileño. 1921-1997. Educador popular. Entre sus obras de impacto sobre la actividad que se describe, se destacan La educación como práctica de la libertad (Río de Janeiro: Paz e Terra, 19ª ed., 1989); Pedagogía del oprimido (Nueva York: Herder y Herder, 1970); ¿Extensión o comunicación? (Río de Janeiro: Continuum, 1971); La acción cultural para la libertad y otros escritos (Buenos Aires: Tierra Nueva, 1975); La educación y el cambio (Río de Janeiro: Continuum,1981).

${ }_{48}$ "Carta a un maestro", en Zumerland, Colonia de vacaciones (Ediciones Colonia, 1965), 47.
} 
en forma privada y en la traducción al castellano de documentos originalmente elaborados o publicados en idish. ${ }^{49}$

Entonces, el abordaje testimonial es una oportunidad de privilegio cuando se trata de reponer información que ha quedado guardada en las memorias y como género expresivo, que además de transmitir, es una fórmula estructurante de la identidad individual y grupal.

Yo me identifico con una generación que estaba muy bien representada en el ICUF y que estaba también representada fuera del ICUF en el sentido de pensar que éramos parte de un proceso positivo, que se iba a llegar a una nueva sociedad, que quizás nosotros no lo íbamos a ver, pero que los hijos de nuestros hijos probablemente la vieran y que cada cosa que hacíamos tenía un sentido, no era simplemente por el hoy sino que éramos parte de un proceso histórico. Entonces cuando digo "nosotros" me refiero a eso, a ese concepto [...] que todos somos de alguna forma peones en un proceso histórico [...] el hecho de ser solidario no solamente tiene que ver con la persona a la cual uno está apoyando, sino también tiene que ver con que también te modifica a vos mismo. ${ }^{50}$

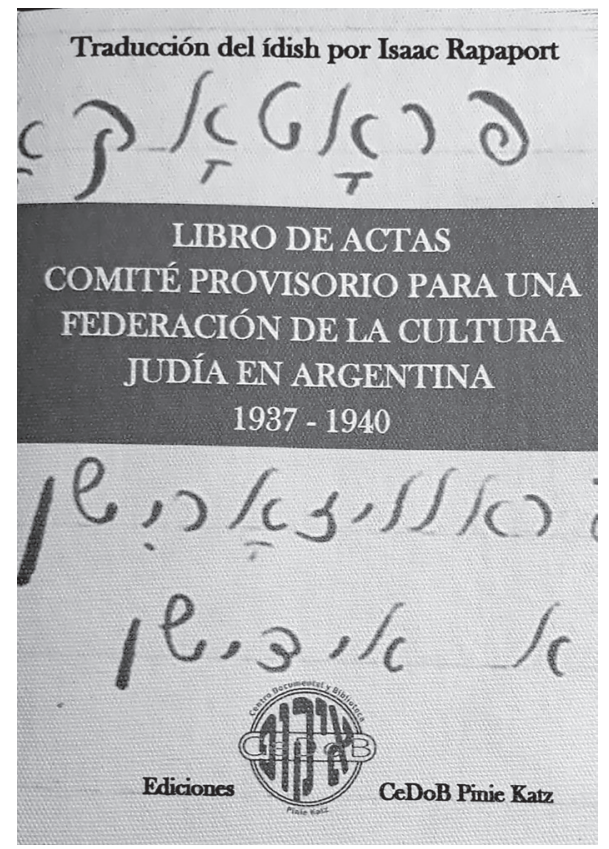

llustración 5. Traducción del idish al castellano de las actas del Comité Provisorio para una Federación de la Cultura Judía en Argentina (Buenos Aires: Ediciones CeDoB Pinie Katz, 2019).

${ }^{49}$ En 2017 se funda el Centro Documental y Biblioteca Pinie Katz con el propósito de ordenar, preservar y conservar fuentes primarias y secundarias que den cuenta de la historia de las instituciones icufistas de las provincias argentinas y de Montevideo, Uruguay. Está en contacto con centros de investigación afines nacionales e internacionales.

50 Pablo Schimilovich, docente participante de la kinderclubeada 1975. Testimonio oral. (Buenos Aires: 2011). 
Al tomar posición, contando o respondiendo a interrogaciones, no hay inocencia ${ }^{51}$, se da cuenta de hallazgos, se asignan sentidos a vivencias, se revisan y valoran experiencias. Se trata de mediaciones significativas entre textos internos -ideas, sentimientos- propios o apropiados, reposicionados, a partir de los que se instala una forma de transmisión que además de fortalecer, marca pertenencia a un tiempo y a una comunidad de afinidades. ${ }^{52}$

El relato como recorte narrativo, además de poner en línea memoria e historia, acuerdos y controversias internas, semantiza experiencias, rescata vivencias y genera fuentes no sustituibles que amplían la comprensión de procesos individuales y sociales complejos. ${ }^{53}$

En las actividades lo que hacíamos era tomar lo mejor de cada cosa [...] porque en este proceso de construcción de valores, no es que vamos a ser solidarios con construir una silla de ruedas, tampoco era una cosa de beneficencia. Era que lo que tenemos que lograr, lo tenemos que lograr entre todos y yo creo que era algo más, un algo que atravesaba las actividades [...] Así sería el hombre nuevo. ${ }^{54}$

El capital simbólico ${ }^{55}$ repuesto con un racconto que retorna sobre lo experimentado requiere el reconocimiento de la condición de labilidad de la memoria ${ }^{56}$ y de lo idiosincrático de la asignación de sentidos, así como la posibilidad de involucrarse y distanciarse de los acontecimientos de los que se habla.

Quienes abordan con sus testimonios hechos distantes y además atravesados por lo traumático, reponen, en muchos casos, ausencias con representaciones, con "invención" de imágenes, construyendo registros que socializan recuerdos -y responsabilidades- y organizan categorías propias para interpretarlos.

Hay un axioma que descubrí hace mucho [...] no se puede transmitir lo que no se contiene y hay aspectos de la transmisión, cuando conducís, cuando sos dirigente, que no se pueden transmitir si no los contenés. Y cuando digo contención me refiero no a lo visceral, no a lo cognitivo, me refiero a qué te pasó por adentro, qué viviste [...] esas cosas de la percepción, la sensación, las cosas más primarias con el olfato, con la vista, con el gusto, con las emociones más básicas [...] la praxis. Vale la teoría. Claro que vale la mirada teórica, crítica, constructiva a partir de esa propia mirada sobre la práctica. ${ }^{57}$

La trama urdida entre testimonios que vencieron el olvido, algunas fotos recuperadas casi por casualidad y unos pocos documentos guardados por organizadores permitió reponer en la memoria institucional, de los participantes de entonces y de nuevas generaciones

\footnotetext{
${ }^{51}$ Jerome Bruner, La fábrica de historias. Derecho, literatura, vida. (Buenos Aires: Fondo de Cultura Económica, 2003), 32.

${ }^{52}$ Ana Diamant, Silvia Dutrenit, "Vivir clandestinos pensando en volver: historias de vida de comunistas uruguayos en Buenos Aires durante la dictadura", en Historia, voces y memoria (Buenos Aires: Facultad de Filosofía y Letras, Universidad de Buenos Aires, 2015), 42.

${ }^{53}$ Dora Schwarzstein, De Franco a Perón. Memoria e identidad del exilio republicano español en Argentina (Barcelona: Crítica, 2001), 16.

${ }^{54}$ Guillermo Golzman, docente participante de la kinderclubeada 1975. Testimonio oral. (Buenos Aires: 2012).

${ }_{55}$ Carlos Altamirano, Términos críticos de sociología de la cultura (Buenos Aires: Editorial Paidós, 2002), 11.

${ }^{56}$ Joel Candau, Memoria e identidad (Buenos Aires: Ediciones Del Sol, 2001), 92.

${ }^{57}$ Inés Moreno, Directora Central de Kinderclubs. Responsable pedagógica de la actividad recreativa del ICUF al momento de la realización de las kinderclubiadas (1972-1975). Testimonio oral (Buenos Aires: 2012).
} 
de icufistas una experiencia que a la luz de los sucesos acontecidos en simultáneo y posteriores adquiere la forma, además de acto militante, de verdadera proeza.

\section{La actividad: producciones para la paz}

En 1975, en el contexto de una Argentina en democracia que iba perdiendo intensidad mientras se fortalecían aparatos represivos paraestatales, rodeada por dos países -Chile y Uruguay- en dictadura, el movimiento icufista apuesta a la continuidad de una actividad que contravenía criterios básicos de cuidado y seguridad: la kinderclubeada, de la que participaban niñas y niños de 10 a 12 años en una estancia de dos días en el medio rural, fuera de sus casas, lejos de sus familias, acompañados por docentes y activistas ${ }^{58}$, con el objeto de ensayar acciones sostenidas en la vocación pacifista, internacionalista y solidaria de la organización convocante:

Me acuerdo de los juguetes, eso sí que me acuerdo. Los juguetes, en mi caso eran de madera, yo no sé si todos fueron de madera, yo era maestro. ${ }^{59}$

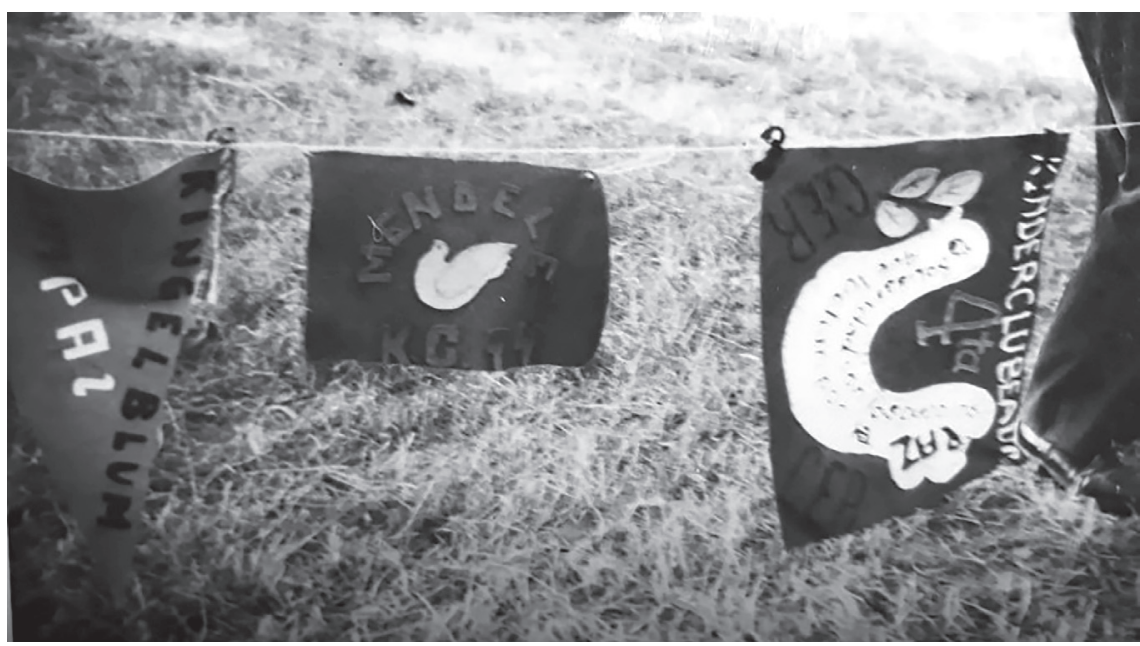

llustración 6. Banderas institucionales. Realizadas con anterioridad a la actividad. Producción colectiva.1975.

La dimensión del desafío y hasta el riesgo es posible evaluarlos más de cuarenta años después, revisando los acontecimientos políticos que se sucedieron-que dejaron un saldo de 30000 desaparecidos, junto con un gran número de exiliados, presos, ciudadanos confinados a una vida casi clandestina- pero también de los antecedentes que sostuvie-

\footnotetext{
${ }^{58}$ Adultos voluntarios no profesionales que acompañaron la actividad.

${ }^{59}$ Pablo Schimilovich, docente participante de la kinderclubeada 1975. Testimonio oral. (Buenos Aires: 2011).
} 
ron los principios fundacionales de las instituciones que participaron y de los modos de funcionamiento posterior.

No hay una forma de educar que sea apolítica o aideológica. Quien lo diga, implícitamente está tomando postura [... Siempre hay un compromiso, lo que no implica, que sea un compromiso político de filiación con un determinado partido. Yo en ese momento sí tenía una afiliación política partidaria, pero la verdad que ni me asustaba eso ni me asustó el tema de bajada de línea. En toda institución hay una forma de mirar el mundo y la vida. En nuestras instituciones había una buena forma de mirar el mundo y la vida que, además, coincidía con un momento. ${ }^{60}$

Convocar a producir para la paz fue una actualización de los fundamentos ideológicos y políticos que operaron y operan como reparatorios y colectivos presentes desde que se inicia en una tierra distante de los escenarios originales el accionar de una colectividad judeo progesista que aloja no sólo sobrevivientes de las guerras europeas, también recuerdos de vivencias extremas, que en el caso de la segunda guerra mundial dejó sesenta millones de muertos, de los cuales, seis millones fueron judíos.

\begin{abstract}
Esto no era una actividad aislada y quizás eso era la clave del asunto, no es que de repente un día decíamos: vamos a hacer una actividad solidaria con Uruguay o Chile [...] con los grupos mayores se habìa hablado de Uruguay y de Chile (...) Creo que una de las grandes virtudes que tuvo el trabajo era la coherencia, la vinculación, no éramos una isla [...] Cuando llega el momento de hacer una actividad solidaria no es que a los pibes les suena... ¿y esto qué? Sino que era una cosa natural, no era forzada y entonces me parece que eso es una cosa de coherencia interna que se venía haciendo. Yo recuerdo [...] que fue con las inundaciones de Santa Fe, que hubo unas inundaciones y que los grupos mayores fueron para allá a... a llevar ropa y a llevar cosas pero me acuerdo que el concepto era: nosotros no hacemos beneficencia [...] fueron, ayudaron, ayudaron a pintar, a limpiar, hicieron actividades con los chicos que estaban en galpones porque sus casas estaban inundadas... eso es coherencia, una coherencia en cuanto al concepto de solidaridad [...] solidaridad con el que necesita nuestra ayuda y eso me parece que es importante. Que quizás yo por eso te traigo lo de la kinderclubeada [...] era una actividad normal $[. .$.$] es lo que hacemos, no genera ningún tipo de conflicto. { }^{61}$
\end{abstract}

Fueron dos los ejes que atravesaron esta experiencia: la solidaridad con los pueblos en lucha por la paz con un fuerte componente internacionalista y la producción de objetos concretos que materializaran el propósito que articuló la actividad.

Los ejes se hicieron materialización en juguetes que luego fueron enviados a pares que convivían con sus madres en cautiverio - de los que no queda ningún registro documental- murales, esculturas, letras de canciones, algunas de las cuales perviven.

Volver a aquellos días, pasado tanto tiempo, desde testimonios y muy pocos documentos invita a discutir categorías tales como temporalidad, significatividad y fertilidad de la experiencia, a la luz del tiempo transcurrido y de las consideraciones valorativas y también teóricas que se le pueden asignar hoy.

${ }^{60}$ Guillermo Golzman, docente participante de la kinderclubeada 1975. Testimonio oral (Buenos Aires: 2012).

${ }_{61}$ Pablo Schimilovich, docente participante de la kinderclubeada 1975. Testimonio oral. (Buenos Aires: 2011). 


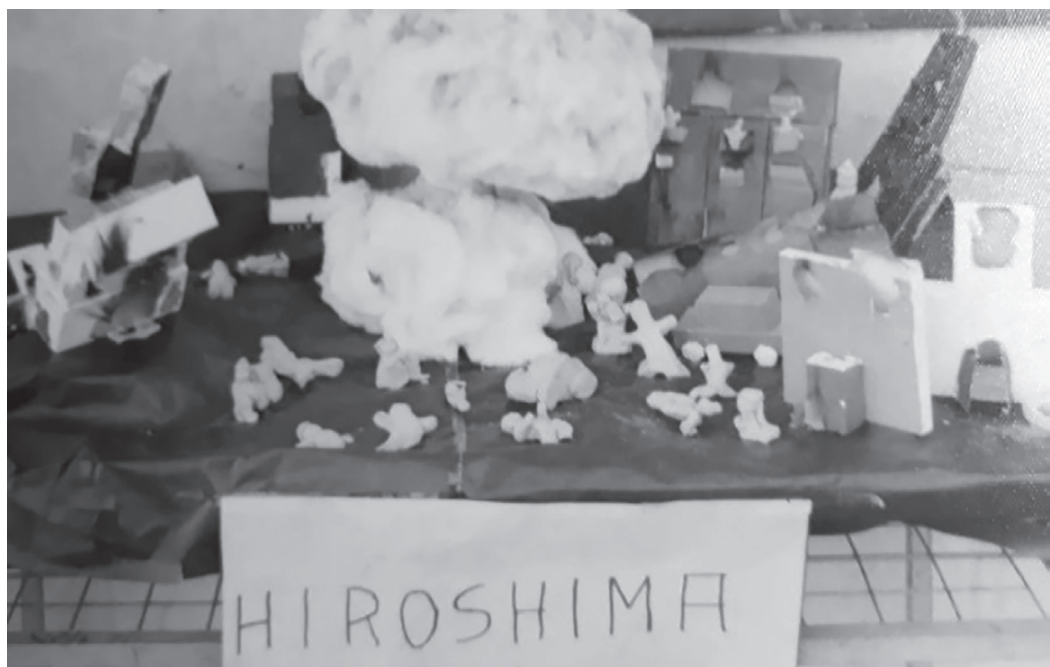

llustración 7. Hiroshima. Escultura en cartón, papel, madera y algodón.

Habíamos invitado a un uruguayo y a un chileno para que charlaran en los fogones y respondieran preguntas. Se hicieron carteleras, actividades de reflexión y artísticas. Por supuesto, además se jugó, se cantó, se hicieron deportes y todo lo que se hace habitualmente para disfrutar y pasarla bien en grupo, compartiendo y aprendiendo a ser solidarios en las actitudes cotidianas. ${ }^{62}$

Se trata de un conjunto de maniobras de recuperación y recontextualización, no sólo de un evento y sus marcas, también de marcos teóricos, de poner en cuestión aportes originales para una propuesta pedagógica y reconocer en ella logros, posibles incoherencias y hasta contradicciones.

Allí se pusieron en juego, además de los propósitos ideológicos y su mediación pedagógica, las tensiones en algunos casos con los aprendizajes escolares, en relación con las formas pactadas de trato entre pares y con adultos, la posibilidad de su transferencia a otros espacios, las realizaciones mediadas por la voluntad compartida, las transmisiones de valores y conductas consideradas deseables. ${ }^{63}$

Fue un ensayo -no el único ni el primero- que ayudó a experimentar los alcances de conceptos vinculados a lo valioso, lo autorizado, lo aceptado, lo vedado, hacerse cargo de las consecuencias sobre decisiones tomadas, sin dejar de lado el placer y sobre todo lúdico, atravesado por la especificidad coyuntural de un contenido: el pacifismo, entornado por el internacionalismo y la solidaridad, sostenido con las propuestas pedagógicas críticas propias de la época.

\footnotetext{
${ }^{62}$ Silvia Poliakoff, La re-creación y re-construcción del mural de la canilla del medio. La historia contada a los grupos (Buenos Aires: Mimeo, 2010), 3.

${ }^{63}$ Ana Diamant, "Génesis y continuidad de un proyecto de educación no formal en el tiempo libre. Testimonios de 60 años de la colonia Zumerland en Argentina", Anuario de Historia de la Educación, 12 (2012): 7.
} 
Esa actividad, la Kinderclubeada, fue la última actividad politizada que pudo hacerse tanto en la colonia como en los $\mathrm{KC}^{64}$ antes de la dictadura. Porque ya habían comenzado las persecusiones también en nuestro país y luego en marzo de 1976 también aquí tuvimos un golpe de estado, en el que sucedieron hechos tan terribles como los que sucedían en Chile y Uruguay. ${ }^{65}$

\section{Un mural como huella del pasado}

El tiempo protegió algunas marcas materiales de aquella actividad y de lo producido.

Una de ellas fue un mural que sobrevivió casi abandonado durante veinticinco años, que se fue deteriorando en un espacio muy concurrido -el comedor de la colonia- "transparentado" en la cotidianeidad de las experiencias que se sucedieron por años, hasta que un grupo de niños de la misma edad de sus originales autores, con sus docentes, decidieron intervenirlo y recuperarlo en 2010.

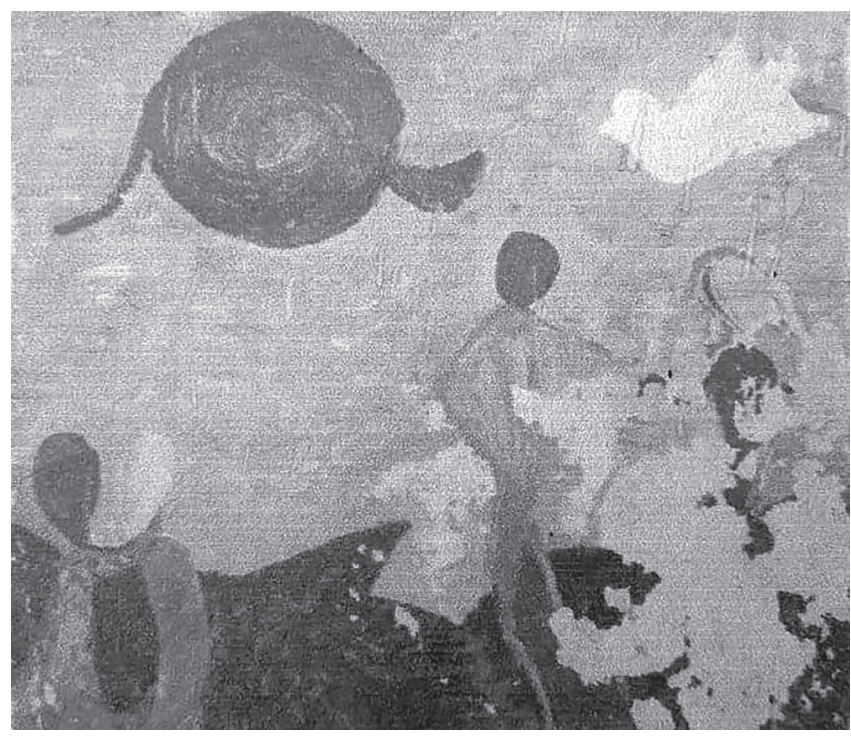

Ilustración 8. Mural. Producción colectiva. Kinderclubeada 1975.

El análisis del material testimonial surgido de la tarea de poner en valor el mural, representativo de una época y sobre todo de una ideología -que incluye pocas voces de los originales autores y muchas más de quienes intervinieron en él veinticinco años después -es una especie de viaje en el tiempo que permitió y permite transitar la experiencia antigua y actualizarla. Una experiencia contundente, instituyente, en la que la construcción colectiva se hace presente como clave de supervivencia.

\footnotetext{
${ }^{64}$ Kinder Club en idish, club infantil.

${ }^{65}$ Silvia Poliakoff, La re-creación y re-construcción del mural de la canilla del medio. La historia contada a los grupos (Buenos Aires: Mimeo, 2010), 3.
} 
La dictadura ya pasada, el retorno a la democracia, plantearon nuevas controversias en relación con objetos, símbolos y posturas vinculadas a la convivencia en grupos, la autogestión, la autoridad emancipatoria, el intercambio entre niños y adultos, el derecho a la alegría, a la comunicación, a la libre expresión y los nuevos temas para abordar en una actividad voluntaria en el tiempo libre.

Miraron con mucho asombro y preguntaron porqué estaba así el mural [...] y se pusieron de gran charla a preguntar y preguntar para entender qué había pasado en aquel tiempo [...] Realmente yo no podía creer que hicieran preguntas tan inteligentes, con tanta información y profundidad. Y que se mostraran además con tantas ganas de aprender a realizar esa misteriosa tarea de recrear, reconstruir. ${ }^{66}$

La prolongada y silenciosa presencia del mural y la recuperación de su protagonismo hicieron que se transformara en un objeto conmemorativo y convocante a la discusión. Los trayectos de vida, las diferencias generacionales, las formas de procesar recuerdos le adjudicaron nuevos significados desde el presente.

La conexión generacional ${ }^{67}$ y los intercambios entre adultos jóvenes y niñas y niños que se generaron a su alrededor hicieron que además de compartir un destino común, le adjudicaran sentidos de contemporaneidad diferentes, que se recuperaran huellas distantes de acuerdo a cómo habían quedado registradas en las viejas biografías y cómo se incorporaba a las nuevas.

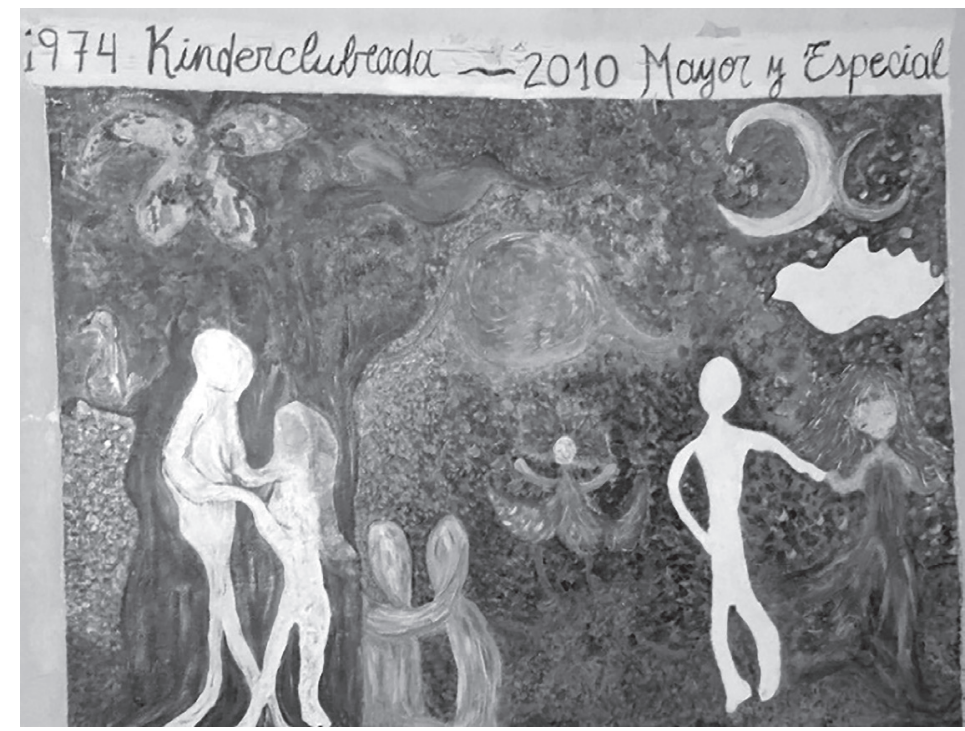

Ilustración 9. Mural intervenido. Producción colectiva. Zumerland, Grupos Mayor y especial. 2010.

\footnotetext{
${ }^{66}$ Idem, Ibidem

${ }^{67}$ Silvia Dutrenit, Aquellos niños del exilio. Cotidianidad entre el Cono sur y México (México: Instituto Mora. Colección Testimonios, 2015), 23.
} 
Sabés que el año pasado vivimos una experiencia que para algunos viejos resultó muy conmovedora. Mientras vos fabricabas juguetes de madera, otros hicieron un mural que quedó en el comedor nuevo donde había niños [pintados] [...] un grupo de chicos de distintos grupos se plantearon restaurar el mural y allí donde ya no quedaban colores eligieron poner blanco y no restituir los colores. Cuando les preguntamos por qué [dijeron que] incluyeron a los desaparecidos... esos blancos. ${ }^{68}$

Para ese momento, además de la dictadura, la guerra de Malvinas, el juicio a las juntas militares responsables de crímenes de lesa humanidad, la visibilización de organismos de derechos humanos, fueron todas informaciones y experiencias vitales que los niños y las niñas que treinta y cinco años después habitaron los mismos espacios conocían, y se abordaron también en términos de contenidos en las actividades recreativas promovidas por las mismas instituciones icufistas.

Así apareció un enorme árbol, un pájaro colorido que luego se convirtió en mariposa, un loro barranquero, otro pájaro cantor y elegante, la pareja de amigos volvieron a abrazarse, otra pareja llegó muy enamorada, salió un enorme sol y vino una luna loca. También apareció una niña bailando muy contenta y la pareja de aquella época se dio la mano, regresando para no irse nunca más. ${ }^{69}$

La actualización de la existencia del mural desencadenó una nueva serie de producciones. Un poema escrito por un niño de doce años que participó de la tarea de restauración es elocuente en términos de transmisión generacional.

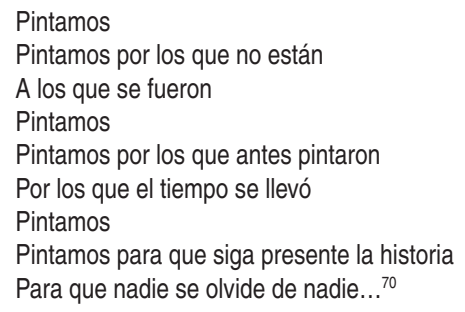

Los jóvenes restauradores interpelaron y se interpelaron desde su tiempo, sus vivencias y en relación con la transmisión que pudieron hacer los originales autores. Junto a los docentes resignificaron la experiencia que resultó reparatoria para personas, pero sobre todo para el acervo cultural y de memoria de la institución.

Con las narrativas polifónicas que reconstruyeron una trayectoria -en este caso de una actividad puntual- fueron testigos de confrontaciones sobre formas, fechas, circunstancias de la producción referida. Incorporaron, al tiempo que trabajaban en la intervención -porque técnicamente no fue una restauración-, relatos que como todos, no fueron neutros, que trasuntaron conflictos, pero que de todos modos ayudaron a unir, para ese auditorio, lo

\footnotetext{
${ }^{68}$ Pablo Schimilovich, docente participante de la kinderclubeada 1975. Testimonio oral. (Buenos Aires: 2011).

${ }^{69}$ Knopp Lila y Poliakoff Silvia, "El proceso", en La re-creación y re-construcción del mural de la canilla del medio.

La historia contada a los grupos (Buenos Aires: Mimeo, 2010), 7.

${ }^{70}$ Manuel, 12 años. Participante de la restauración. 2010.
} 
que se esperaba con lo que aconteció, intentando construir una armonía entre el pasado reciente y el presente.

Este mural representa, desde lo que pudimos reconstruir, la paz, el amor y la amistad (...) Hicimos el mural por los que fueron, los que están, los que no encontramos y por los que hicieron el mural para demostrar que a pesar de todo lo que pase, el amor y la amistad van a seguir viviendo dentro de todos los que son, fueron y serán. ${ }^{71}$

El lenguaje resulta a la vez un recurso y un contenido, pone marcas distintivas a los relatos, ayuda a reconstruir situaciones y coloca a las experiencias pasadas en un presente en el que lo épico, lo nostálgico, las sensaciones de pertenencia hacen nuevos escenarios y dan lugar a nuevos protagonistas.

Memoria, comunidad, tiempo y relato se ligan en la construcción de discursos y en la interacción y permiten nuevos productos sociales y culturales que se enriquecen con nuevos documentos y con la consolidación de nuevas identidades.

Hubo una propuesta de ponerle un nombre al mural. Hubo muchos aportes individuales: "Jardín de la verdad", "Los que no están, los desaparecidos", "Noche y día en la paz de Zumerland", "Alegría y color" y muchos otros. Finalmente una construcción colectiva que dejó una nueva marca: "Noche y día en el jardín de la verdad. Colores presentes, blancos desaparecidos".

Esa marca, que ya es de otro pasado, constituye ahora un punto de inflexión en la memoria, en el discurso, en la vida, en la materialidad de un objeto, en el análisis a partir del que, seguramente, se hilvanarán nuevas historias, nuevos relatos, nuevos significados:

Me gustó la idea de restaurar lo que hicieron hace 36 años, es como ir al pasado. ${ }^{72}$

\section{La actividad como confluencia de significados}

Con aquellos juguetes de los que se perdió vestigio, con las esculturas que se fueron degradando con el paso del tiempo y con el mural restaurado que presentifica varios pasados, hubo y sigue habiendo presencias y ausencias, datos descriptivos o explicativos, transmisión de valores y actitudes.

Hay presencias materiales, espaciales, de linajes. Hay ausencias marcadas por el tiempo y también por las desapariciones forzadas. Hay datos descriptivos en materiales que se pudieron guardar y poner luego a circular. Hay datos explicativos en las voces de testigos y sobrevivientes. Hay transmisión de valores y actitudes no sólo en las reactualizaciones, también en las nuevas producciones.

En la tensión entre pasado y presente, que es de algún modo marcar el futuro, recuperar, reponer, son oportunidades de posicionar a otros, desconocidos, que estuvieron antes

\footnotetext{
${ }^{71}$ Lucía, 12 años. Participante de la restauración. 2010.

72 Matías, 12 años. Participante de la restauración. 2010.
} 
en los mismos espacios que ahora recorren nuevas generaciones al amparo de nuevos proyectos, que sosteniendo los principios institucionales genéticos, no le temen a los tiempos con sus demandas sociales muchas veces distantes de las originarias.

Asumir fragmentos del pasado que pueden -y aceptan- ser reelaborados, confrontados a la luz de nuevos posicionamientos teóricos, culturales, generacionales, generan a la vez incomodidad y estímulos hacia lo nuevo. Otra vez jugar entre pasado presente y futuro de los tiempos y de las vivencias.

Se aprende de la mutación de los objetos, del contenido del relato en pasado, de la posición del relator o entonces productor en el presente, de la autopercepción, de las tensiones entre hechos e interpretaciones, entre objetos y representaciones, de las coherencias y de las contradicciones, de que la paz no es ausencia de conflicto, sino presencia de acuerdos justos.

Se enseña -aún en tiempos difíciles- en instituciones educativas fuera del sistema formal, que son enclaves para el cuidado y la experimentación de formas contra-hegemónicas, para elaborar nuevos valores, cuestionar reglas habituales, fomentar el compromiso colectivo, producciones culturales y los vínculos con el entorno.

Así se construyen legados fundantes de sentidos, interpretaciones que estructuran imaginarios que trascienden los tiempos del presente.

Así nuevas generaciones de docentes, niñas y niños, recorren y producen, producen mientras recorren, rescatando objetos e historias que de otro modo quedarían condenadas al olvido.

\section{Bibliografía}

AAVV. "A la Icufiada, Salud!". Tiempo 59 (1973): 11 - 12.

AAVV. "Pasar a la ofensiva". Tiempo 48 (1972): 20.

AAVV. "El ICUF. Pujante movimiento judeo progresista". En X Congreso. Buenos Aires: Edición de la Federación de Entidades Culturales Judías de la Argentina. 1972.

AAVV. Tesis de la Conferencia Sudamericana del ICUF. Montevideo: Edición de la Federación de Entidades Culturales Judías, 1967.

Altamirano, Carlos. Términos críticos de sociología de la cultura. Buenos Aires: Paidós, 2002.

Camarero, Hernán. Tiempos rojos. Buenos Aires: Sudamericana, 2017.

Candau, Joel. Memoria e identidad. Buenos Aires: Ediciones Del Sol, 2001.

Bruner, Jerome. La fábrica de historias. Derecho, literatura, vida. Buenos Aires: Fondo de Cultura Económica, 2003.

Brusilovsky, Silvia. "Recuperando una experiencia de democratización institucional y social: la extensión universitaria en la Universidad de Buenos Aires (1955 - 1966)". 
Revista de Investigaciones del Instituto de Ciencias de la Educación 12 (1998): $31-41$.

Diamant, Ana. "Una experiencia de solidaridad e internacionalismo fuera de la escuela. La propuesta de fabricar juguetes desde una institución judeo progresista argentina para niños uruguayos y chilenos (1974-1975)". En Actas XX Coloquio Internacional de Historia de la Educación: Identidades, Internacionalismo, Pacifismo y Educación: 547 - 552. Monforte de Lemos: Sociedad Española de Historia de la Educación, 2019.

Diamant, Ana. "Génesis y continuidad de un proyecto de educación no formal en el tiempo libre. Testimonios de 60 años de la colonia Zumerland en Argentina". Anuario de Historia de la Educación 12 (2012): 209-336.

Diamant, Ana. "Una noble y gran generación, de pie hacia la realidad. Los años `60 y la formación de niños y adolescentes en instituciones judeo progresistas del Río de la Plata". En Actas XXXIII ISCHE: Estado, educación y sociedad, nuevas perspectivas sobre un viejo debate: 64 - 82. San Luis Potosí: Universidad Autónoma de San Luis Potosí, 2011.

Diamant, Ana and Jorge Feld. Zumerland Colonia. Proyecto, memorias. Buenos Aires: Ediciones CER, 2000.

Diamant, Ana and Silvia Dutrenit. "La militancia clandestina uruguayo porteña: comunistas en el exilio". Revista Estudios 38 (2017): 47-68.

Diamant, Ana and Silvia Dutrenit, "Vivir clandestinos pensando en volver: historias de vida de comunistas uruguayos en Buenos Aires durante la dictadura". Historia, voces y memoria 8 (2015): 37-50.

Dutrenit, Silvia. Aquellos niños del exilio. Cotidianidad entre el Cono sur y México. México: Instituto Mora. Colección Testimonios, 2015.

Katz, Pinie. Páginas selectas. Buenos Aires: Editorial ICUF, 1980.

Kaufmann, Carolina, Nora Lijtmaer y Roxana Muri Nicastro. Shules y ateneos. Huellas de la educación no formal judeorosarina. Rosario: Editorial Laborde, 2008.

Kinoshita, Dina Lida. "O ICUF como uma rede de intetectuais", Revista Universum 15 (2000): $370-389$.

Kresfeld, Daniel. Rusos y rojos. Judíos en los tiempos de la Comintern. Buenos Aires: Capital Intelectual, 2012.

Poliakoff, Silvia, Knopp. Lila. La re-creación y re-construcción del mural de la canilla del medio. La historia contada a los grupos. Buenos Aires: Mimeo, 2010.

Schwarzstein, Dora. De Franco a Perón. Memoria e identidad del exilio republicano español en Argentina. Barcelona: Crítica, 2001. 
Tokman, Ariel. "De Gorki a Zumerland y de la U.R.S.S. a Mercedes: Diálogos históricos entre pedagogías disonantes". Anuario de Historia de la Educación 19, volumen 1 (2018): $66-85$.

Visacovsky, Nerina. Argentinos, judíos y camaradas tras la utopía socialista. Buenos Aires: Biblos, 2015.

\section{Repositorios testimoniales}

Golzman, Guillermo. Buenos Aires, 2012.Testimonio oral.

Kogan, Leike. Buenos Aires, 1999. Testimonio oral.

Lucía, 12 años. Mercedes, Pcia. de Buenos Aires, 2010. Testimonio escrito.

Manuel, 12 años. Mercedes, Pcia. de Buenos Aires, 2010, Testimonio escrito.

Matías, 12 años. Mercedes, Pcia. de Buenos Aires, 2010. Testimonio escrito.

Moreno, Inés. Buenos Aires, 2012. Testimonio oral.

Schimilovich, Pablo. Buenos Aires, 2011. Testimonio oral.

\section{Repositorios documentales}

Libro de Actas. Comité Provisorio para una Federación de la Cultura Judía en Argentina (1937-1940) Traducción Isaac Rapaport. Buenos Aires: Ediciones CeDoB Pinie Katz, 2019.

Manifiesto, Primer Congreso Mundial de la Cultura Judía, 1937. Buenos Aires: Mimeo, 1967, en La Educación en las Entidades del ICUF. Pasado, presente y futuro. Buenos Aires: Mimeo. 2011.

Zumerland Colonia de Vacaciones. Ediciones Colonia, s/datar. Buenos Aires: Mimeo, ca 1962-65.

Instructivo elaborado por el equipo de conducción de la actividad entregado a docentes y voluntarios participantes. Incluye además horarios de actividades, normas de convivencia y de higiene personal, recursos para la conducción de los grupos y materiales disponibles para la realización de las tareas. Buenos Aires: Mimeo, 1975.

Conclusiones. Plenario Nacional de la Juventud del ICUF. Buenos Aires: Mimeo, 1974. 